SOTO ARANGO, DIANA ELVIRA.

\title{
La escuela rural en colombia. Historias de VIDA DE MAESTRAS. MEDIADOS DEL SIGLO XX
}

(TUNJA: FUDESA,2014) ISBN 978-958-58380-0-0

Por: Jose Enrique Cortez

Universidad San Carlos de Guatemala

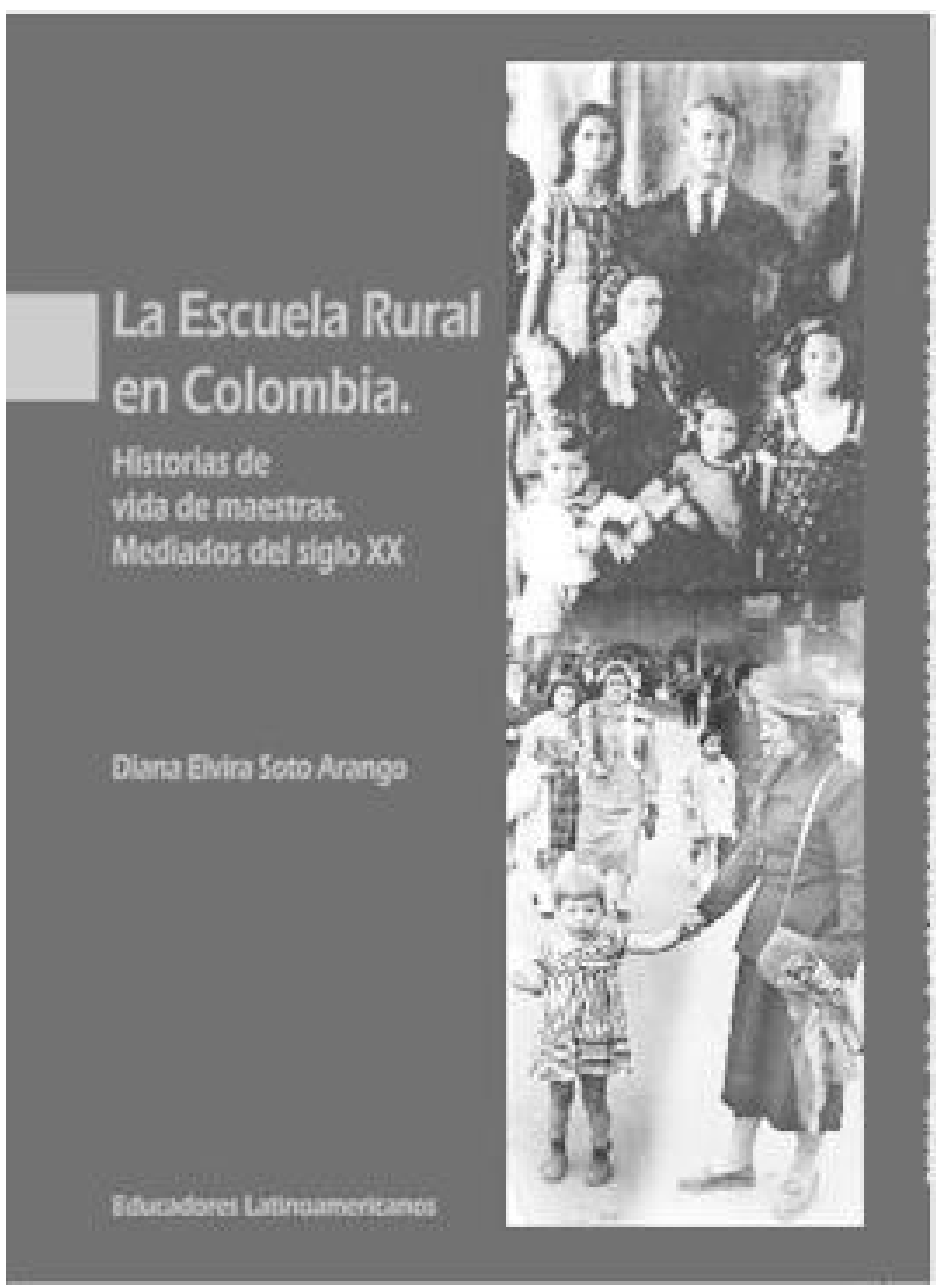

La educación en Colombia ha tenido una serie de cambios en la estructura organizativa y técnica; así como en el desempeño de las docentes y los docentes. El contenido del presente libro escrito por la Doctora Diana Elvira Soto Arango, da a conocer la incidencia que han tenido dos maestras que laboraron en el Sistema Educativo y que desarrollaron su labor en el área rural y urbana, en donde dejaron su mejor esfuerzo para mejorar las condiciones de vida de la población y por ende experimentaron acciones que las llevó a ser cada día mejor, tanto personal, profesional y laboralmente.

Se trata de las historias de vida de las maestras Amparo Arango y Andrea Linares, ambas con fases de vida diferentes, ejercen la docencia según el ambiente laboral, familiar y social en donde se desenvuelven.

La primera se inicia en el municipio de Cundinamarca para luego llegar al área rural del municipio de Boyacá en donde finaliza su labor docente y se jubila; la segunda maestra, tuvo su formación en un centro educativo en el área urbana de Cundinamarca y posteriormente trabaja en el área rural y se jubila, luego finaliza en el medio urbano de Bogotá. 
Según Soto, D. (2014), "El hilo conductor, de la investigación, se establece desde la diferencia política e ideológica de las dos maestras: una liberal y la otra conservadora10, con historias de vida diferentes, pero ambas inmersas en una labor educativa de impacto social, local y de cambio de mentalidad en lo referente a la educación de la mujer". Es evidente destacar que los resultados de la investigación de estas dos connotadas maestras tienen un impacto en le visibilización de la mujer colombiana y aún más en las maestras que por su condición femenina no han sido tomas en cuenta como debiera de ser en una sociedad en donde el ejercicio docente tiene gran relevancia por el desempeño de maestras y por consiguiente de maestras rurales. 